\title{
EL LEGADO COLONIAL Y EL DESARROLLO REGIONAL EN COLOMBIA*
}

\author{
JAIME BONET ${ }^{\mathrm{a}}$ \\ ADOLFO MEISEL ROCA ${ }^{\mathrm{b}}$ \\ CEER. Banco de la República
}

\begin{abstract}
RESUMEN
Este trabajo utiliza los aportes teóricos y empíricos de la reciente literatura internacional sobre los determinantes del crecimiento económico de largo plazo, para explicar el origen histórico de las enormes desigualdades económicas regionales que caracterizan a Colombia. Los resultados indican que la geografía y la cultura no son un determinante directo de las diferencias en el ingreso per cápita regional. Sin embargo, la geografía tuvo un papel central pero indirecto, a través de su influencia en los patrones de poblamiento durante el período colonial. Si bien las estimaciones econométricas muestran la enorme influencia del legado colonial sobre las diferencias contemporáneas en los ingresos departamentales, no es claro si el efecto opera vía las instituciones o el capital humano.
\end{abstract}

Palabras clave: Geografía, instituciones, desigualdad, desarrollo económico, ingreso regional

Clasificación JEL: N16, N26, N96, O18, R11

* Received 04/24/2007. Accepted 12/11/2007. Este trabajo ha sido financiado por el Centro de Estudios Económicos Regionales (CEER) del Banco de la República (Banco Central de Colombia).

a jbonetmo@banrep.gov.co - 57 - 5 - 6600808 Ext 152.

b ameisero@banrep.gov.co - 57 - 5 - 6600761. 


\begin{abstract}
This paper uses the theoretical and empirical contributions of recent international literature on the determinants of long run economic growth to explain the historical origin of the enormous regional economic inequalities which characterize Colombia. The results indicate that geography and culture are not direct determinants of differences in regional per capita income. Nevertheless, geography did play a central but indirect role through its influence on settlement patterns during the colonial period. Although econometric estimations indicate that the colonial legacy influenced contemporary differences in regional income, it is not clear if this effect operates via the institutions or human capital.
\end{abstract}

Keywords: Geography, Institutions, Regional Income, Economic Development

JEL classification: N16, N26, N96, O18, R11

\title{
1. INTRODUCCIÓN
}

Los trabajos recientes que analizan las diferencias en los ingresos entre países encuentran varios determinantes principales, los cuales, de acuerdo con Acemoglu et al. (2005), se pueden agrupar en tres categorías: instituciones, geografía y cultura. Los autores que defienden el papel de las instituciones consideran que la organización de la sociedad es la clave para el desarrollo económico en el largo plazo. En este enfoque las sociedades que ofrecen incentivos y oportunidades para la inversión serán más ricas que las que no lo hacen. Por el lado de la geografía, se argumenta que estas variables son esenciales en la determinación de la productividad de ciertos factores, como la mano de obra y la tierra, lo que, a su vez, determina el éxito económico relativo de los países. Otros autores argumentan que el determinante clave del desarrollo es la cultura, entendiéndola como los elementos compartidos por una sociedad que determinan los valores, las preferencias y las creencias de los individuos. En ese enfoque juegan un papel clave la confianza que existe entre los miembros de una sociedad, las creencias religiosas y la participación de los individuos en la vida colectiva, entre otros.

Las diferencias que persisten en los ingresos per cápita entre los países se presentan también entre las regiones de un país. Para el caso colombiano, de acuerdo con las cifras recientes de ingreso departamental producidas por el CEGA (2006), estas desigualdades se mantuvieron estables durante el período 1975-2000. Al analizar el ingreso bruto per 
cápita, se encuentra que la unidad territorial con mayor ingreso durante todo el período fue Bogotá, mientras que el departamento con menor ingreso por habitante fue Chocó.

El ingreso bruto per cápita de Bogotá es similar al observado en aquellos países clasificados como de ingresos medio altos por el Banco Mundial, tales como Croacia o Polonia, mientras que el nivel de Chocó se equipara a los reportados para países de ingresos bajos, tales como Zambia o Vietnam. Las estadísticas del Banco Mundial para 2005 indican que, en promedio, los países de ingresos medio altos tienen rentas por habitante que son entre ocho y diez veces más altas que aquellas reportadas en los países de ingresos bajos. Esta relación es muy similar a la que se mantiene entre Bogotá y Chocó durante el período analizado.

La persistencia en las diferencias en el ingreso regional colombiano, con una clara hegemonía económica de Bogotá y el empobrecimiento de las áreas periféricas ${ }^{1}$, obligan al análisis de la evolución del nivel de ingreso per cápita regional en Colombia: ¿Cuáles son los determinantes del desempeño económico de las regiones en el largo plazo? ¿Por qué unas regiones se mantienen muy por encima del promedio nacional, mientras que otras se mantienen por debajo? ¿Cuál es el papel que juegan las instituciones, la geografía y la cultura en este resultado?

Contestar las preguntas anteriores es, precisamente, el objetivo de este documento compuesto de cuatro secciones. Inicialmente, se hará una revisión de la literatura que sobre el tema se ha desarrollado en estudios internacionales y nacionales. La siguiente sección se centra en el análisis empírico de los determinantes del ingreso bruto per cápita departamental. Finalmente, el último apartado presenta las conclusiones del trabajo.

\section{REVISIÓN DE LA LITERATURA}

En los últimos años, los economistas se han interesado nuevamente por discutir cuáles son los determinantes últimos del desempeño económico en el largo plazo. Hasta hace poco tiempo, una gran cantidad de trabajos empíricos se concentraban en el análisis de los determinantes más directos del crecimiento, tal como se desprende del análisis neoclásico: capital físico, capital humano y productividad. Este enfoque tiene el problema que sus resultados son casi tautológicos: los países más prósperos son los que tienen más capital físico y humano y, por tanto, mayores aumentos en la productividad.

1 Para un mayor detalle sobre las disparidades en el ingreso per cápita departamental en Colombia ver Bonet y Meisel (2006). 
Sin embargo, la pregunta más interesante es saber por qué razón hay países con mayores niveles de capital físico, capital humano y alta productividad. En esta materia, el historiador económico Douglass C. North ha argumentado que son las instituciones las que determinan el desempeño económico en el largo plazo. Para North (1990), las instituciones no son las organizaciones sino las reglas del juego, formales e informales, que regulan la actividad económica y política. Aunque los trabajos de North fueron muy influyentes en la década de 1990, inicialmente hubo muy pocos trabajos empíricos, pues no resultaba fácil encontrar mediciones adecuadas de algo tan complejo como las instituciones. Sin embargo, esa situación ha venido cambiando a partir de los primeros años de la década del presente siglo, cuando algunos investigadores económicos, de manera muy creativa, han desarrollado variables que nos permiten aproximarnos a la medición de las instituciones.

Dentro de la literatura empírica reciente sobre las causas del crecimiento económico en el largo plazo, Hall y Jones (1999) argumentan que la infraestructura social es lo que explica las enormes diferencias en los niveles de producción por trabajador que se observan entre los países. Para esos autores, la infraestructura social está compuesta de las instituciones y las políticas gubernamentales ${ }^{2}$. Estos autores prefirieron trabajar con el nivel del producto y no con su tasa de crecimiento, pues se ha observado una gran variabilidad en el crecimiento en las diferentes décadas. Una situación similar ocurre en el caso colombiano, razón por la cual en este trabajo se ha preferido trabajar con los niveles de ingreso ${ }^{3}$.

A finales de la década de 1990, el economista Jeffrey Sachs y otros investigadores (Gallup et al., 1999; Sachs, 2001; McArthur y Sachs, 2001) empezaron a proponer un papel directo de la geografía en el desarrollo económico. La tesis de Sachs y sus asociados es que para entender el desarrollo económico en el largo plazo se debe estudiar la geografía física, pues ésta tiene un efecto directo en la prosperidad económica relativa de las naciones. Esa influencia se da principalmente a través de la productividad agrícola, la salud y el acceso a las vías de comunicación.

Tal vez los trabajos más influyentes en la reciente literatura empírica acerca de las raíces del crecimiento económico secular han sido los de Acemoglu, Johnson y Robinson (2001, 2002, 2005). Estos autores argu-

\footnotetext{
${ }^{2}$ Knack y Keefer $(1995,1997)$ desarrollaron unos trabajos previos para evaluar el impacto de lo que ellos llamaron capital social en el crecimiento de un grupo de países.

3 Hall y Jones son conscientes de un posible problema de endogeneidad al estimar el modelo econométrico, ya que el nivel del producto puede afectar también la infraestructura social. Por esa razón, usan variables instrumentales, tales como variables de localización (distancia a la línea del ecuador) e idiomas. La última refleja la influencia de Europa Occidental y la primera lo atractivo que podía ser el sitio para los inmigrantes europeos.
} 
mentan que con la expansión colonial europea a partir del siglo Xv, se crearon en muchas partes del globo arreglos institucionales nuevos que afectaron, en el curso de los siguientes siglos, la distribución espacial de la prosperidad económica en el Nuevo Mundo. Todo ello como fruto de la colonización y conquista europea. Las instituciones que surgieron en las diferentes zonas del mundo no resultaron igual de eficientes para el crecimiento económico de largo plazo en el ingreso per capita. Por esa razón, es importante preguntarse: ¿De qué dependió que en unas partes se establecieran unas buenas instituciones y en otras no?

La respuesta de Acemoglu y sus asociados es que el tamaño relativo de la población colonizadora europea con respecto al resto de la población (nativos o esclavos traídos del África), fue lo que determinó el tipo de instituciones que surgió en cada lugar. Entre más pequeña era la población de colonizadores, más extractivas fueron las instituciones que se crearon. A su vez, el tamaño relativo del grupo colonizador estuvo determinado por la salubridad de los sitios, ya que los europeos evitaban emigrar a aquellas partes del globo en las que había una alta mortalidad. Esa alta mortalidad estaba determinada, en gran medida, por la geografía física: distancia del ecuador y altitud, entre otras. En el trópico, enfermedades como la malaria y la fiebre amarilla frenaban la llegada de los europeos ${ }^{4}$.

A diferencia de Acemoglu et al., para quienes el tipo de instituciones que surgen como resultado del colonialismo está relacionado con el peso relativo de los conquistadores en la población total, para Engerman y Sokoloff (1997) el tipo de instituciones que legó el colonialismo dependió de la dotación inicial de factores (incluyendo tipos de suelos, climas y el tamaño y densidad de la población nativa), la cual predispuso a las sociedades del Nuevo Mundo para que siguieran por sendas de crecimiento económico con grados diferentes de desigualdad en la distribución de la riqueza, el capital humano y el poder político.

En la argumentación de Engerman y Sokoloff, en aquellos sitios donde se podían cultivar productos con grandes economías de escala, era muy atractivo introducir esclavos para trabajar en las plantaciones. En contraste, en aquellos sitios donde los productos agrícolas que se podían cultivar no presentaban grandes economías de escala, y no había una abundancia de población nativa o de recursos minerales para explotar, la distribución de la riqueza inicial entre los colonizadores fue bas-

${ }^{4}$ Acemoglu et al. usaron el método de variables instrumentales para corregir los posibles problemas de endogeneidad. En la primera etapa estimaron la variable instituciones en función de la mortalidad de los europeos en el momento de la colonización. Dicha mortalidad tiene la característica que está altamente correlacionada con la medida que los autores usaron para las instituciones, pero no con el ingreso per cápita actual, excepto por la vía de las instituciones. 
tante equilibrada. Esto permitió la consolidación de instituciones donde predominaba una gran igualdad de oportunidades.

Otros autores cuyo trabajo empírico sigue un enfoque muy similar al de Acemoglu, Johnson y Robinson, son Easterly y Levine (2003) y Rodrik, et al. (2004). Los dos artículos utilizan tres tipos de variables para explicar el nivel del ingreso per cápita de un grupo de países. En ambos trabajos se usan como variables independientes medidas de la geografía física y las instituciones. Además, en el de Easterly y Levine se incluye una variable de políticas económicas y en el de Rodrik et al. una de integración económica. Al igual que Acemoglu y sus asociados, estos autores utilizan mínimos cuadrados en dos etapas en las estimaciones para evitar el problema de la posible doble causalidad del ingreso hacia las instituciones. En los dos artículos se concluye que la principal variable explicativa del ingreso per cápita son las instituciones y que la geografía no afecta directamente el ingreso, excepto vía las instituciones.

Un artículo muy crítico de los trabajos empíricos recientes que argumentan que las instituciones son la principal razón de la prosperidad relativa de las naciones, es el de Glaeser, La Porta, Lopez-De-Silanes y Shleifer (2004). Para estos autores, las instituciones son un producto del crecimiento económico y no su determinante, ya que con el desarrollo las instituciones van mejorando. Glaeser y sus coautores cuestionan los resultados empíricos y argumentan que los europeos que llegaron al Nuevo Mundo no sólo trajeron instituciones, sino también su capital humano. Además, agregan que fue ese capital humano, tanto históricamente como en el presente, lo que impulso el crecimiento económico.

En las ciencias sociales hay una larga tradición que le atribuye por lo menos una parte de las diferencias en los niveles de prosperidad económica a la cultura. Uno de los más célebres trabajos en esta línea fue el libro escrito por el sociólogo alemán Max Weber (1930). Para Weber, la ética protestante, en especial en su versión calvinista, creaba actitudes favorables para las virtudes burguesas del trabajo disciplinado, el ahorro y la austeridad. En contraste, eso no ocurría con el catolicismo; por esa razón, argumentaba este autor, a comienzos del siglo xx las regiones más prosperas de Europa eran las del norte, precisamente donde había una mayoría Protestante, mientras que el sur, que era predominantemente católico, tenía muchas de las zonas más pobres de Europa.

En un trabajo reciente, Tabellini (2005) realizó un análisis empírico de la influencia de la cultura en el desempeño económico de las regiones de Europa. Para ello utilizó como variables independientes medidas de valores individuales, tales como la confianza, el respeto por los demás y las creencias sobre la relación entre el esfuerzo individual y el éxito económico. Esa información la obtuvo de encuestas realizadas en la década de 1990. 
En el caso de Colombia, García (2005) explora el impacto de las instituciones coloniales sobre el desempeño económico contemporáneo de los municipios colombianos. A pesar de que el trabajo de García realizó un importante esfuerzo para la reconstrucción de variables históricas, ciertas variables limitan el análisis. Por ejemplo, uno de los indicadores de desempeño económico escogido es el Gini de la distribución de la tierra, la cual no tiene una asociación clara con el desempeño económico en Colombia, ya que estas dos variables no tienen una relación estadísticamente significativa entre sí $^{5}$. Otra variable con problemas es el número de indígenas tributarios, pues lo importante desde el punto de vista de las instituciones es el tamaño relativo de la población colonizadora y no el número absoluto de nativos.

\section{ANÁLISIS EMPÍRICO DE LOS DETERMINANTES DEL INGRESO PER CÁPITA DEPARTAMENTAL}

\subsection{Aproximación metodológica}

En la especificación de nuestro modelo, y con el objetivo de realizar una primera exploración de los determinantes del ingreso anteriormente expuestos para el caso colombiano, estimamos la siguiente regresión lineal por Mínimos Cuadrados Ordinarios (MCO):

$$
\begin{gathered}
\gamma_{i}=\beta_{0}+\beta_{1} \text { Instituciones }_{i}+\beta_{2} \text { Geografía }_{+} \beta_{3} \text { Cultura }+ \\
+\beta_{4} D \_ \text {Bog }+\beta_{5} D \_ \text {Nue }+\varepsilon_{i}
\end{gathered}
$$

Donde $\gamma_{i}$ es el ingreso bruto departamental per cápita de 2000, Instituciones $_{i}$ es una de las posibles medidas de instituciones, Geografía ${ }_{i}$ es una de las variables geográficas propuestas y Cultura $_{i}$ es una de las proxy planteadas para medir la cultura. Debido a las circunstancias singulares de la capital del país, se ha incluido en la estimación la variable dummy para Bogotá $D \_B o g_{-}$, con el objeto de controlar por los problemas potenciales que pueda generar esta observación. Adicionalmente, se incluye otra variable dummy para los llamados Nuevos Departamentos, ya que éstos presentan un cambio significativo en su nivel de ingreso como consecuencia de la explotación de yacimientos petroleros en algunos de sus territorios.

El subíndice $i$ corresponde a los departamentos colombianos. Considerando las limitaciones de información disponible, este trabajo

\footnotetext{
${ }^{5}$ El coeficiente de correlación del Gini de la distribución de la tierra y el PIB per cápita departamental del 2003 es estadísticamente igual a cero. Un resultado similar se obtiene utilizando el ingreso bruto departamental per cápita de 2000.
} 
incluye 25 entidades territoriales: los 23 antiguos departamentos, los nuevos departamentos consolidados y Bogotá. Los $\beta_{i}$ son los coeficientes de interés y $\varepsilon_{i}$ el tradicional término de error con media igual a cero.

El principal problema de la anterior especificación econométrica es la posible presencia de endogeneidad en la variable instituciones. Precisamente, la evidencia muestra que la manera como las instituciones evolucionan hace que muchas de ellas se determinen simultáneamente. Por ello, para corregir la posibilidad de la endogeniedad, lo que se reflejaría en unos estimadores de MCO inconsistentes, se utilizó una estimación en dos etapas con variables instrumentales.

\section{Primera etapa}

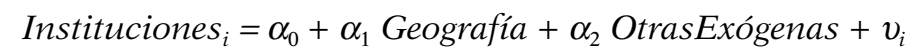

Segunda etapa

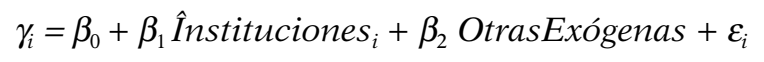

Donde las variables se definen como en el modelo inicial. corresponde a los valores proyectados a partir de la regresión de la primera etapa y otras exógenas corresponden a aquellas variables que resulten significativas en la explicación de las diferencias en los ingresos en las estimaciones iniciales de MCO.

\subsection{Especificación de las variables}

Las variables utilizadas tienen diferentes fuentes. El ingreso departamental bruto per cápita del año 2000 fue tomado de CEGA (2006) y se presenta en pesos constantes de 1994. En las estimaciones esta variable se incluye en logaritmos.

La variable instituciones se mide de dos maneras. En primer lugar, se usa la presencia de regimenes esclavistas en los distintos territorios, estimada a través del porcentaje de esclavos en 1843 y en 1851. En una segunda instancia, hemos calculado el porcentaje de población de origen europeo que en la actualidad tiene cada departamento, como un indicador del tamaño relativo del grupo colonizador en el total de la población departamental. La lógica detrás de esta última variable es que aquellas regiones con un tamaño relativo mayor de colonizadores, construyeron instituciones más equitativas, las cuales fomentaban un mayor dinamismo económico. De esta manera, se espera una relación positiva entre el tamaño relativo del grupo colonizador y el ingreso per cápita, mientras 
que una relación inversa es lo que se espera entre el porcentaje de esclavos y el nivel de ingreso. La información sobre esclavitud se tomó directamente de los censos de población de los años respectivos y los datos sobre la población de origen europeo se tomaron de un estudio del genetista Emilio Yunis (2003) ${ }^{6}$.

Es muy difícil encontrar una proxy para las diferencias regionales en la cultura. Para el caso colombiano, donde la población ha sido mayoritariamente católica, lo que se trató de hacer fue ver la posible incidencia relativa (mayor o menor presencia) de esta religión en el comportamiento económico de cada departamento. Para ello se construyeron dos variables: las participaciones de los eclesiásticos y religiosas en la población de 1843 y 1851 . Se esperaría que una mayor presencia de la relación católica tenga una incidencia positiva con el nivel de ingreso, pues tradicionalmente la iglesia católica ha sido más débil en las zonas periféricas, donde existe una mayoría de población indígena y afrodescendiente. Esta información se tomó de los censos de población para esos años.

Consideramos importante incluir una variable que refleje la participación de los colombianos en la vida política. Como lo menciona Gamarra (2006), a pesar de que existe en el país un marco jurídico uniforme que promueve la participación ciudadana, la forma como se utilizan los mecanismos establecidos no es homogénea entre los distintos territorios, debido a que la influencia del clientelismo varía a través del país.

Para medir la incidencia del clientelismo en las diferentes regiones, Gamarra propone usar los resultados de las elecciones atípicas de dos días contiguos que tuvieron lugar en 2003: primero se votó un referendo convocado para reformar la Constitución Política y al siguiente día tuvo lugar la elección de autoridades locales. En la medida en que la primera votación estaría más ligada a un voto de opinión y la segunda a la presencia de las maquinarias locales, las diferencias en las votaciones recogerían el peso de esas maquinarias, o del mismo modo, la madurez participativa de cada departamento. En conclusión, la relación entre los votos válidos del referendo y los de las elecciones de autoridades locales se ha tomado como una proxy de la participación ciudadana departa-

${ }^{6}$ La información se tomó del libro de E. Yunis (2003), ¿Por qué somos así? ¿Qué pasó en Colombia? Análisis del Mestizaje, mapas 13 y 14 para el aporte indígena y negro, respectivamente. El aporte caucásico se estimó por residuo. El valor regional se aplicó para cada uno de los departamentos que la conforman. Para Bogotá se usó el estimado para Cundinamarca. En el caso del aporte indígena, como los datos están reportados en un rango, se tomó el valor promedio. La información para el departamento del Casanare se encontró en José Vicente Rodríguez Cuenca, "Avances de la antropología dental en Colombia», tabla núm. 13, bajado del Internet en la dirección http:/www.colciencias.gov.co/seiaal/documentos/jvrc06c7.html, el día 16 de junio del 2003. 
mental: entre más alta, en términos relativos, la votación en el referendo, menor el peso de las maquinarias políticas locales. De esta manera, se esperaría que una mayor participación electoral se refleje en un mayor nivel de ingreso per cápita departamental.

Para medir la incidencia de la geografía, hemos tomado cinco variables: un índice que se estima a partir del Factor de Humedad de Thornthwaite (FHT), la distancia de la capital del departamento a Bogotá, la altitud sobre el nivel del mar, una dummy para aquellos departamentos con acceso al mar, el porcentaje de suelos cálidos y el porcentaje de suelos fértiles. Se espera una relación positiva entre el nivel del ingreso per cápita departamental y el índice FHT, la altitud sobre el nivel del mar y el porcentaje de suelos fértiles, mientras que una relación negativa se esperaría con el porcentaje de suelos cálidos y con el acceso al mar, en la medida en que los departamentos costeros hacen parte de las zonas rezagadas de Colombia. La fuente de la información geográfica es el Instituto Geográfico Agustín Codazzi ${ }^{7}$.

\subsection{Resultados}

El cuadro 1 presenta los resultados de la primera estimación usando MCO. Luego de realizar diferentes estimaciones del modelo, hemos incluido las combinaciones que consideramos tienen las variables que muestran una mayor confidencia. Para determinar esto, y siguiendo lo sugerido por Sala-i-Martin (1997), se adelantó un ejercicio econométrico que verificó la confidencia estadística de las variables en diferentes combinaciones. Los resultados de este ejercicio se encuentran el Anexo 1 y muestran tres tipos de modelos cuya diferencia fundamental es el cambio de la proxy usada para evaluar el efecto de las instituciones. En el primero se empleó el tamaño relativo del grupo colonizador, mientras que en el segundo y tercero se utilizó la participación de la población esclava en el total departamental en 1843 y 1851, respectivamente.

En general, lo primero que encontramos es que las variables geográficas y culturales no son significativas estadísticamente. Al parecer las variables geográficas son importantes en la determinación de la produc-

7 Para obtener la altitud departamental se ponderó por población la altitud municipal. El porcentaje de suelos en clima cálido se estimó considerando la participación de las áreas ubicadas entre cero y 1.000 metros sobre el nivel del mar en el total departamental. Para determinar el porcentaje de suelos fértiles se tomó la participación de aquellos clasificados como de fertilidad moderada y alta dentro del total departamental. El índice FHT departamental se tomó de Galvis (2001). Debido a que no existe el valor para Bogotá, se tomó como proxy el correspondiente al departamento de Boyacá, ya que ese territorio tiene una altitud promedio cercana al de la capital. 
tividad agrícola pero no del ingreso total. Por ejemplo, en el estudio de Galvis (2001), el índice FHT resulta significativo en la determinación de la productividad agrícola; sin embargo, en nuestro ejercicio no resultó significativo como determinante del ingreso bruto departamental. Lo anterior puede estar reflejando la poca participación que tiene el sector agropecuario en la generación del ingreso del país en la actualidad. Finalmente, es importante destacar que el porcentaje de suelos cálidos y la distancia de Bogotá, a pesar de que reportaron el signo esperado, no resultaron estadísticamente significativos.

Dentro de las variables que modelan las instituciones, el porcentaje de esclavos, aun cuando muestra el signo esperado, no resultó ser estadísticamente significativo. Por su parte, la variable institucional que es robusta en diferentes combinaciones es el tamaño relativo del grupo colonizador, indicando que un número relativo más grande de ellos se refleja en un mayor nivel del ingreso per cápita. Finalmente, las variables dummy — Bogotá y Nuevos Departamentos- también resultan significativas en la mayoría de las estimaciones.

Por último, la columna 9 del cuadro 1 presenta las variables que muestran una mayor confidencia y que, por tanto, explican mejor las diferencias en los niveles de ingreso: el tamaño relativo del grupo colonizador (que reflejaría la presencia de instituciones de propiedad privada), las dummy para Bogotá y para los Nuevos Departamentos. El R ${ }^{2}$ ajustado nos indica que la variación en estas tres variables estaría explicando alrededor del 58 por cien de la variación en los niveles de ingreso departamental bruto per cápita. Sin embargo, esta estimación presenta los problemas de endogeneidad que han sido señalados en la literatura para este tipo de aproximaciones.

El siguiente paso en el análisis fue realizar la estimación en dos etapas con variables instrumentales con el objeto de corregir los posibles problemas de endogeneidad asociados con las instituciones. En la especificación de este modelo seguimos los planteamientos de Acemoglu et al. (2005), en el sentido que el vínculo entre geografía y desarrollo económico se da a través de instituciones. Factores exógenos como la geografía influirán en la constitución de determinadas instituciones en ciertas áreas. En nuestro caso, hemos encontrado que el tamaño relativo del grupo colonizador tiene una correlación importante con el porcentaje de suelos en clima cálido: $-0,45^{8}$. Esto implicaría que los colonizadores europeos se localizaron en una mayor proporción en aquellas zonas con suelos templados y fríos, donde las condiciones climáticas eran más favorables tanto para la salud como para la productividad agrícola (véase gráfico 1).

\footnotetext{
${ }^{8}$ Este coeficiente de correlación es estadísticamente significativo al 2 por cien.
} 


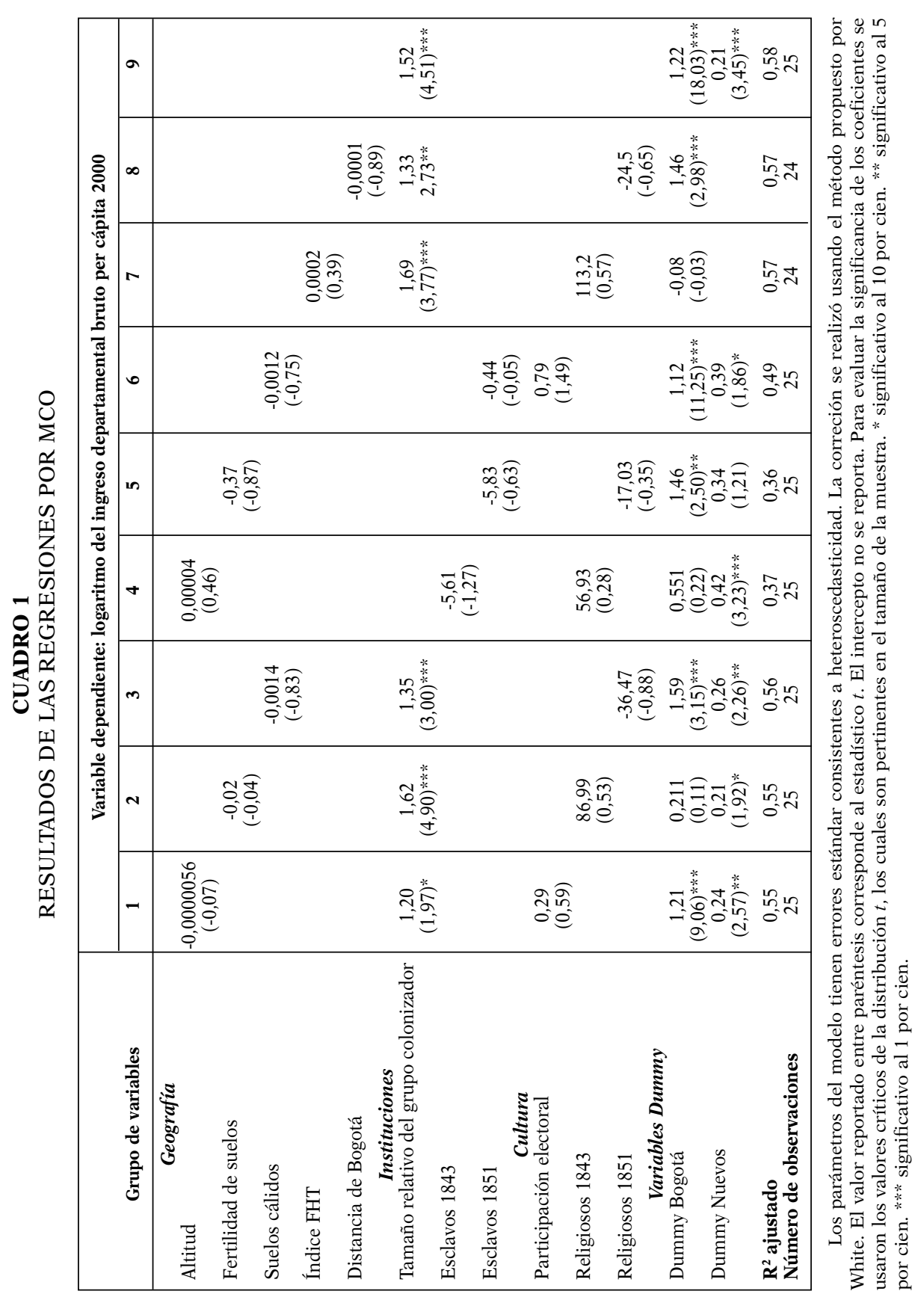


GRÁFICO 1

TAMAÑO RELATIVO DEL GRUPO COLONIZADOR $V S$. PORCENTAJE DE SUELOS EN CLIMA CÁLIDO

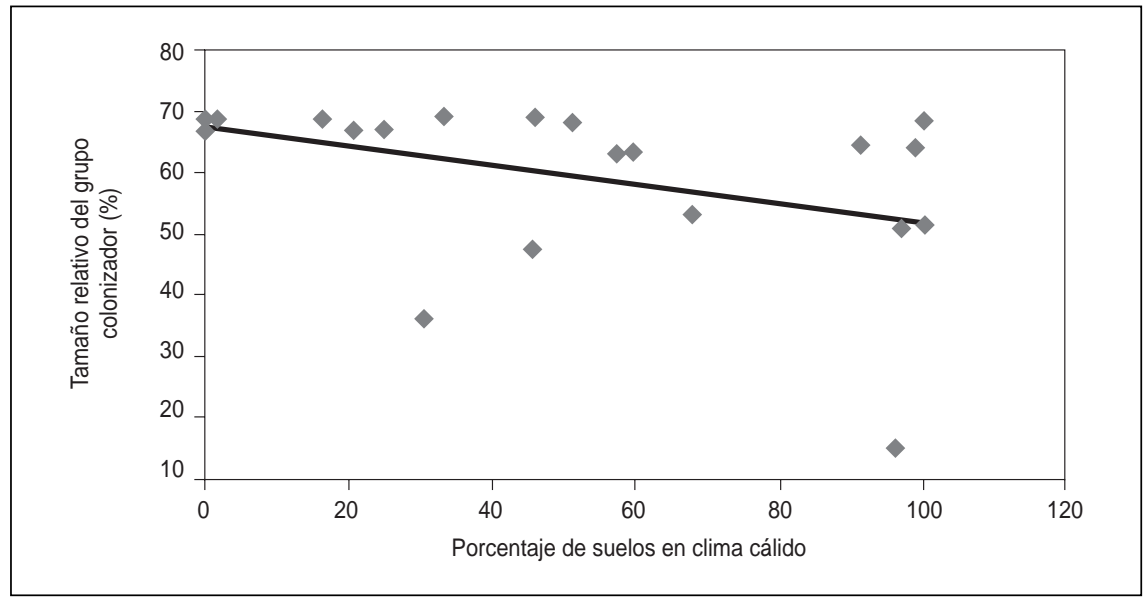

Fuente: Estimaciones de los autores con base en IGAC y Yunis (2003).

Debido a los resultados robustos obtenidos con MCO, para la estimación de mínimos cuadrados en dos etapas (MC2E) hemos mantenido el tamaño relativo del grupo colonizador como la variable proxy que indica qué tan explotadoras fueron las instituciones establecidas a partir de la conquista. Las variables culturales se han eliminado ya que no son estadísticamente significativas. Finalmente, la variable geográfica, específicamente el porcentaje de suelos cálidos, se utiliza como variable instrumental siguiendo lo expuesto anteriormente. Adicionalmente, hemos incluido las variables dummy (Bogotá y Nuevos Departamentos), las cuales también mostraron resultados robustos.

El cuadro 2 incluye los resultados de MC2E con variables instrumentales. Para lograr unos estimadores consistentes, los errores estándar fueron corregidos para eliminar la heteroscedasticidad usando el método propuesto por White. Adicionalmente, considerando que la disponibilidad de datos limita el tamaño de la muestra afectando los grados de libertad, se utiliza la distribución $t$ y no la normal, para estimar tanto el estadístico de prueba como el valor crítico. Lo anterior permite aplicar unas pruebas de significancia más fuertes a los parámetros estimados.

La parte inferior del cuadro 1 corresponde a la primera etapa, donde se analiza la relación entre el tamaño relativo del grupo colonizador y el porcentaje de suelos cálidos, la cual muestra una alta significancia y el signo esperado. La parte superior contiene la segunda etapa de la esti- 
CUADRO 2

RESULTADOS DE LA REGRESIÓN CON VARIABLES INSTRUMENTALES

\begin{tabular}{|lc|}
\hline \multicolumn{2}{|c|}{ Segunda etapa } \\
\hline \multicolumn{2}{|c|}{ Variable dependiente: logaritmo del ingreso departamental bruto per cápita 2000 } \\
\hline Tamaño relativo del grupo colonizador estimado & 2,07 \\
& $(2,4)^{* *}$ \\
Dummy Bogotá & 1,17 \\
& $(14,65)^{* * *}$ \\
Dummy Nuevos & 0,18 \\
& $(2,86)^{* * * *}$ \\
$\mathbf{R}^{2}$ ajustado & 0,55 \\
Número de observaciones & 25 \\
\hline \multicolumn{1}{|c|}{ Variable dependiente: tamaño relativo del grupo colonizador } \\
\hline & $-0,001685$ \\
\hline Suelos cálidos & $(-2,56)^{* * *}$ \\
Dummy Bogotá & $-0,01$ \\
& $(-0,26)^{* * *}$ \\
Dummy Nuevos & 0,12 \\
$\mathbf{R}^{2}$ ajustado & $(3,11)^{* * * *}$ \\
Número de observaciones & 0,13 \\
\end{tabular}

Los parámetros del modelo tienen errores estándar consistentes a heteroscedasticidad. La correción se realizó usando el método propuesto por White. El valor reportado entre paréntesis corresponde al estadístico $t$. El intercepto no se reporta. Para evaluar la significancia de los coeficientes se usaron los valores críticos de la distribución $t$, los cuales son pertinentes en el tamaño de la muestra. ${ }^{*}$ significativo al 10 por cien. ${ }^{* *}$ significativo al 5 por cien. ${ }^{* *}$ significativo al 1 por cien.

mación y muestra que gran parte de las diferencias en los niveles de ingreso pueden ser explicadas por las variaciones de las tres variables explicativas: el tamaño relativo del grupo colonizador (las instituciones de propiedad privada) y las dummy para Bogotá y para los Nuevos Departamentos, los cuales arrojaron un alto nivel de significancia y los signos esperados. Se debe destacar que la medida de instituciones se muestra robusta una vez corregido los problemas de endogeneidad; es decir, la variable es robusta aun considerando problemas de especificación en el modelo.

A pesar de que algunos estudios previos en Colombia han utilizado los datos sobre población esclava para aproximar las instituciones, esta variable no resultó significativa en los ejercicios hechos aquí. En nuestro caso, consideramos que el porcentaje actual de población de origen europeo refleja mejor la calidad de las instituciones que se establecieron 
en el país en el período colonial, porque muestran el patrón colonizador. La presencia relativamente mayor del grupo colonizador determinaría el éxito relativo en términos de crecimiento económico en el largo plazo de las diferentes regiones.

Uno de los hechos encontrados por Yunis (2003) es que no existe homogeneidad genética entre los departamentos colombianos; es decir, las regiones varían ampliamente en cuanto a los ancestros geográficos de sus habitantes ${ }^{9}$. Por ejemplo, el porcentaje de ancestros americanos varia de 40-49 por cien en Nariño a sólo 7,5-10 por cien en Chocó. En el caso de los ancestros africanos, el departamento con un porcentaje más elevado es Chocó (76 por cien) y el de menor participación es Boyacá (2,5 por cien). Finalmente, el departamento de Antioquia y los departamentos del eje cafetero (Caldas, Risaralda y Quindío), así como los Santanderes, tienen el más alto porcentaje de ancestros europeos, 65-73 por cien (véase mapa 1) ${ }^{10}$.

Kalmanovitz (2001) analizó el papel que jugaron las personas de origen europeo en el desarrollo económico de las regiones en Colombia en el siglo XIX. Dicho autor menciona que gran parte de las regiones estaban habitadas por campesinos y peones en estado de analfabetismo y superstición, muy atrás en la escala de productividad que podía mostrar un artesano educado, un pequeño propietario alfabeto o un asalariado maquinizado. Sin embargo, se presentaban excepciones en ciertas áreas, tales como Santander y las zonas de colonización antioqueña, predominantemente pobladas por blancos pobres, independientes de los grandes propietarios de tierras, que lograron un reparto más equitativo de la propiedad y niveles educativos más altos que el resto de las provincias.

Jaramillo Uribe (1989) también destaca las características particulares que presentaban Antioquia y Santander en la organización de sus sociedades. Sobre Antioquia, Jaramillo menciona que poseía una sociedad más abierta y dinámica, en cierto sentido más democrática, lo que propició la formación de una clase empresarial que dio fácilmente el salto de una actividad minera y mercantil a la financiera e industrial. En cuanto a Santander, Jaramillo Uribe indica que era una sociedad con escaso componente indígena y africano y fuerte ancestro español en su composición demográfica. La penuria de minas y tierras agrícolas llevó

9 El estudio analizó a cerca de 60.000 colombianos que asistieron al Instituto Colombiano de Bienestar Familiar para estudios de paternidad a partir de 1971 y hasta 1991.

10 Un aspecto que debe tenerse en cuenta en este análisis es que la experiencia colombiana muestra que la migración interna solamente comenzó a ser importante a finales del siglo xx y que gran parte de la migración interna se da al interior de los municipios de un departamento. Para mayor información véase Jaramillo (1999) y Galvis (2002). En materia de migración externa, el país no ha mostrado grandes flujos de migrantes. 
MAPA 1

TAMAÑO RELATIVO DEL GRUPO COLONIZADOR EN LA POBLACIÓN DEPARTAMENTAL

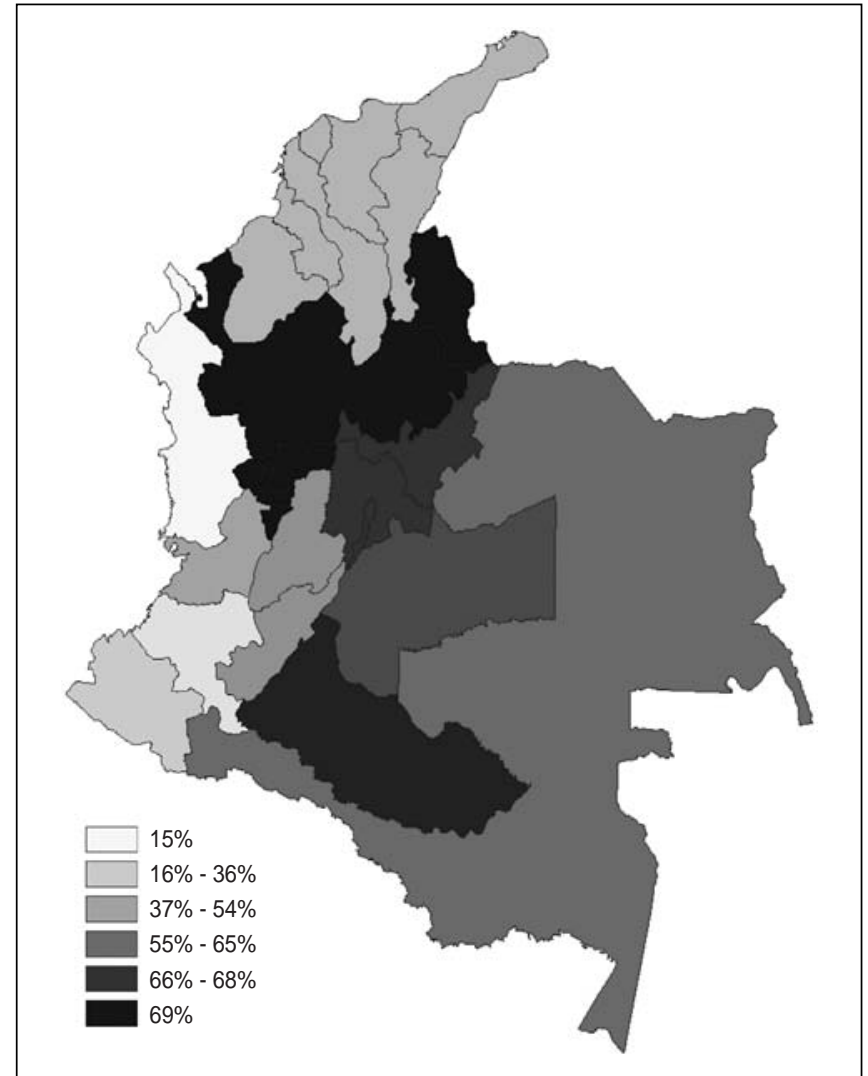

Fuente: Estimaciones de los autores con base en Yunis (2003).

al desarrollo de una industria artesanal, sobre todo de textiles, de mucha importancia.

Por su parte, las Costas Caribe y Pacífica mostraban unos patrones diferentes. La primera era una región agrícola y ganadera de grandes latifundios con uso extensivo de la tierra, con baja inversión en capital y mano de obra mestiza, mulata y esclava. En ella se desarrolló una clase alta de comerciantes y terratenientes que encabezaban una sociedad muy diferenciada, en donde la raza tuvo un papel importante. En las dos provincias que la componían en la era colonial, Cartagena y Santa Marta, sólo el 10,6 por cien de los habitantes eran blancos, de acuerdo 
con el censo de 1778. La Costa Pacífica, por su parte, fue una región minera, agrícola, ganadera y comerciante, con su principal núcleo urbano en Popayán. Estaba dirigida por una élite compuesta por antiguos encomenderos y señores esclavistas. En el caso del Chocó, el departamento más pobre de Colombia en la actualidad, en el censo de 1778 sólo el 2,2 por cien de la población se clasificó como blanca.

Podríamos decir, como lo sugieren Acemoglu et al. (2005), que aquellas sociedades con una mayor presencia del grupo colonizador presentaron un mayor grado de igualdad en las oportunidades, lo cual se reflejaría en que los ciudadanos podían aprovechar adecuadamente las posibilidades de inversión existentes en la economía. La relación inversa entre la proporción del grupo colonizador por departamento y la concentración del ingreso en su territorio, medida a través del índice Gini, se observa en el gráfico 2. En efecto, el coeficiente de correlación entre estas dos variables es -0,46; es decir, que la concentración del ingreso tiende a aumentar a medida que disminuye la proporción de población de origen europeo en la entidad territorial ${ }^{11}$.

Vale la pena señalar que la proxy de las instituciones de propiedad privada usada en las estimaciones econométricas, el tamaño relativo del grupo colonizador, está correlacionada con algunas de las caracte-

GRÁFICO 2

TAMAÑO RELATIVO DEL GRUPO COLONIZADOR VS ÍNDICE GINI DEL INGRESO DEL 2000

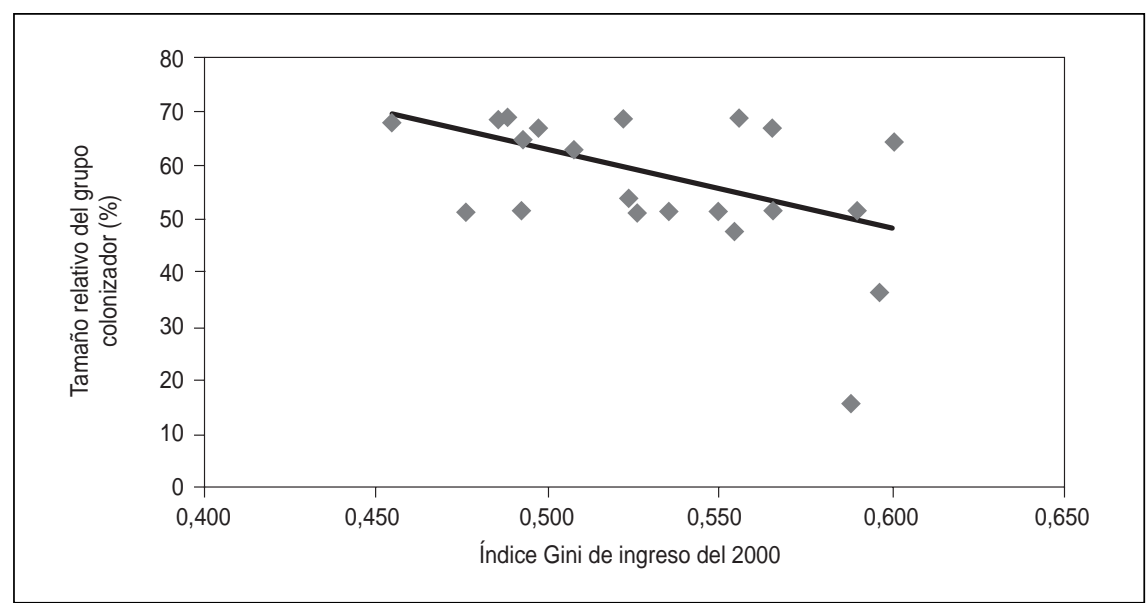

Fuente: Estimaciones de los autores con base en DNP (2003) y Yunis (2003).

${ }^{11}$ Este coeficiente resultó estadísticamente significativo al 2 por cien. 
rísticas que los estudios internacionales atribuyen a las «buenas» instituciones ${ }^{12}$. Es así como una mayor participación relativa del grupo colonizador tiene una correlación importante con la participación ciudadana, con el indicador sintético de desempeño fiscal elaborado por el Departamento Nacional de Planeación y con el indicador de eficacia de las instituciones públicas. Lo anterior implica que, como puede verse en los gráficos 3, 4 y 5, se da una mayor participación ciudadana, un manejo fiscal superior y un mejor uso de los recursos públicos ${ }^{13}$, en aquellos departamentos con una mayor participación del grupo colonizador $^{14}$.

GRÁFICO 3

TAMAÑO RELATIVO DEL GRUPO COLONIZADOR $V S$. PARTICIPACIÓN ELECTORAL

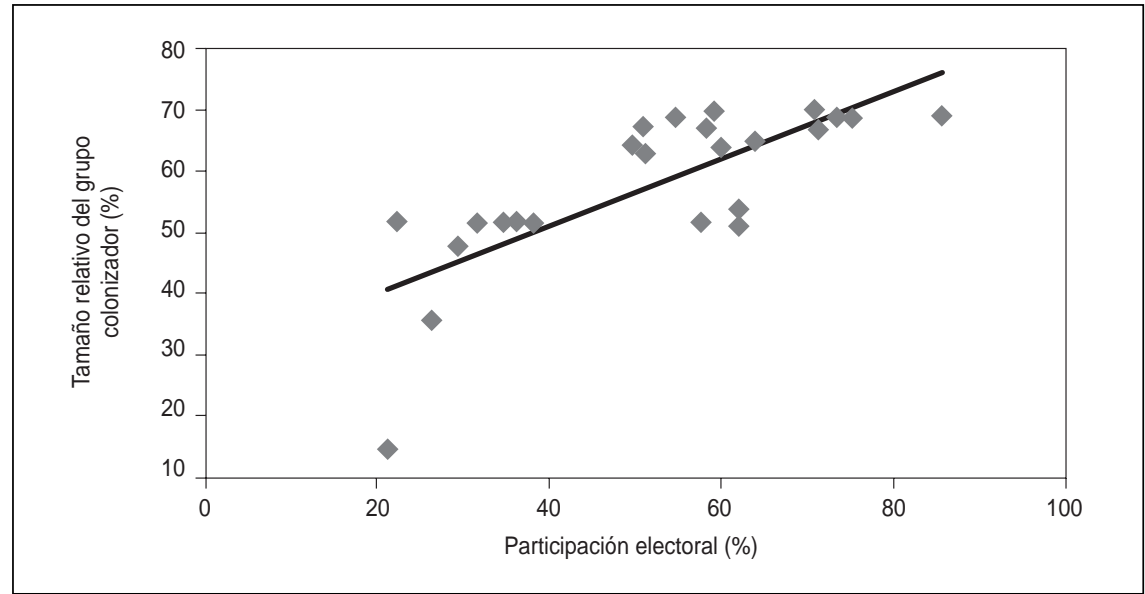

Fuente: Estimaciones de los autores con base en Gamarra (2006) y Yunis (2003).

12 Por ejemplo, Hall y Jones (1999) miden lo que ellos llaman infraestructura social a partir de algunos indicadores como calidad de la burocracia, efectividad del gobierno y corrupción, que se incluyen en la Guía de Riesgo Internacional.

13 Para evaluar el buen uso de los recursos públicos en los departamentos se tomó el índice de Golden y Picci estimado por Gamarra (2006). Este índice se construyó a partir de la relación entre un indicador relativo de la provisión de servicios (en este caso se tomaron salud, educación y saneamiento básico) y un indicador del gasto. Se pretende de esta manera evaluar la eficiencia en el uso de los recursos en la provisión del bien. Una mayor información del procedimiento de estimación se encuentra en Gamarra (2006).

${ }^{14}$ Los coeficientes de correlación entre el tamaño relativo del grupo colonizador y la participación electoral es 0,76 , con el indicador de manejo fiscal del DNP es 0,62 y con el indicador de Golden y Picci es 0,54. Todos resultaron estadísticamente diferentes de cero al 1 por cien. 
GRÁFICO 4

TAMAÑO RELATIVO DEL GRUPO COLONIZADOR $V S$.

INDICADOR DEL MANEJO FISCAL DEL DEPARTAMENTO NACIONAL DE PLANEACIÓN (DNP)

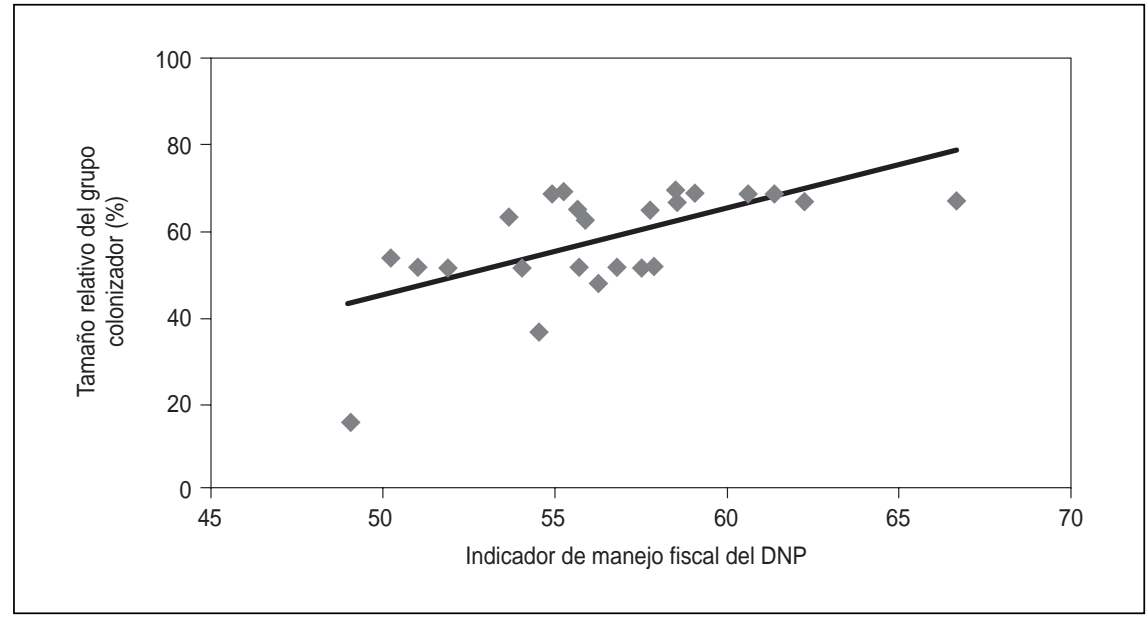

Fuente: Estimaciones de los autores con base en DNP y Yunis (2003).

GRÁFICO 5

TAMAÑO RELATIVO DEL GRUPO COLONIZADOR $V S$.

INDICADOR DE GOLDEN Y PICCI

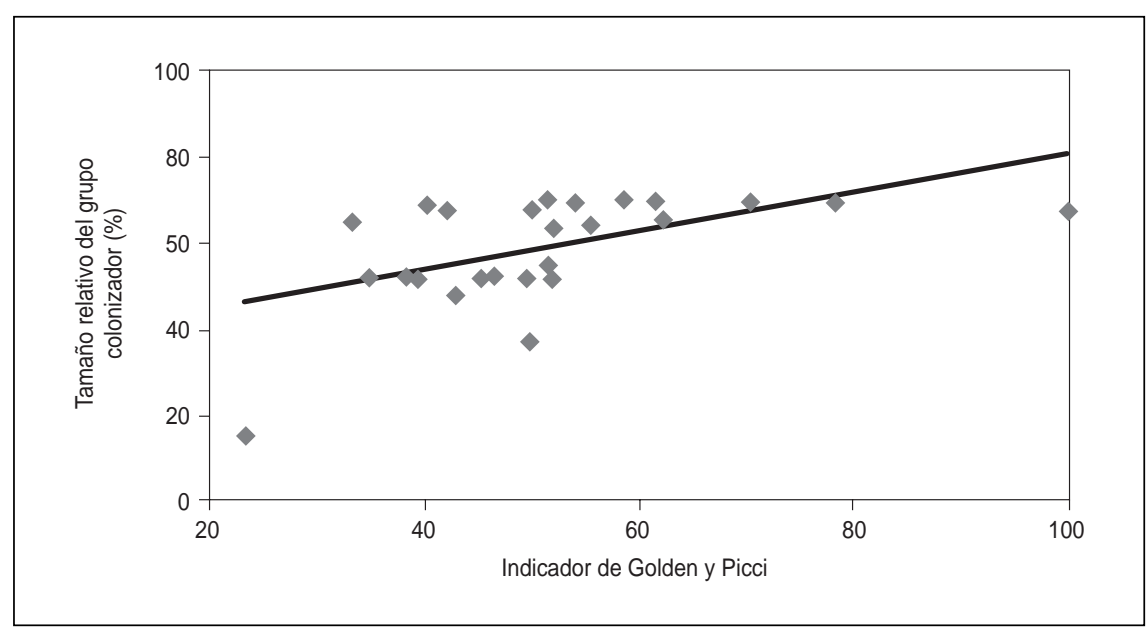

Fuente: Estimaciones de los autores con base en Gamarra (2006) y Yunis (2003). 
La variable dummy para Bogotá, por su parte, está capturando el proceso de aglomeración que ha ocurrido en la economía colombiana durante la segunda mitad del siglo xx. Como lo señalan Krugman y Livas (1996), la razón principal para la concentración industrial en las áreas metropolitanas en América Latina son los eslabonamientos hacia atrás y adelante que estos lugares ofrecen. Las ventajas provenientes de esos enlaces superan las desventajas de dichas aglomeraciones, tales como salarios y arriendos elevados, congestión y polución. En una aplicación del modelo de Krugman y Livas para Colombia, Fernández (1998) encontró que en efecto los eslabonamientos entre sectores inducían a la aglomeración en torno a Bogotá, con una gran influencia también de los costos internos de transporte.

Como se mencionó anteriormente, algunos autores cuestionan el papel de las instituciones en el crecimiento económico. Por ejemplo, Gleaser et al. (2004) argumentan que los conquistadores que se establecieron en el Nuevo Mundo no solo trajeron sus instituciones sino que también trajeron su capital humano. De esta manera, la influencia de los conquistadores europeos no sólo se dio a través de las instituciones que crearon al llegar a los nuevos territorios, sino que influyeron muy especialmente con el conocimiento que trajeron. Gleaser et al. muestran cómo las variables instrumentales usadas en la literatura (las geográficas básicamente) están altamente correlacionadas con el capital humano de hoy y el de 1900. De esta manera, si se estiman modelos econométricos con variables instrumentales para predecir el desempeño económico, el capital humano se comportará mejor que las instituciones.

Para el caso colombiano, hemos tomado la tasa de analfabetismo como indicador del capital humano de los departamentos. Lo primero que encontramos es una asociación inversa entre nuestra variable de instituciones (el tamaño relativo del grupo colonizador) y la tasa de analfabetismo en personas mayores de quince años en 1993. Como puede verse en el gráfico 6, el número de analfabetos es menor en la medida en que la participación del grupo colonizador aumenta ${ }^{15}$. De esta manera, esta variable no solo captura las instituciones como tal, sino que también está incorporando el efecto del capital humano.

Al explorar la relación entre la tasa de analfabetismo y nuestra variable instrumental (el porcentaje de suelos cálidos), encontramos una correlación positiva y significativa, tal como puede verse en el gráfico 7 . El coeficiente de correlación entre estas dos variables es 0,57 , significativo al 1 por cien y mayor al encontrado entre el porcentaje de suelos

15 El coeficiente de correlación entre estas dos variables es $-0,68$, significativo al 1 por cien. 


\section{GRÁFICO 6}

TAMAÑO RELATIVO DEL GRUPO COLONIZADOR $V S$.

TASA DE ANALFABETISMO 1993

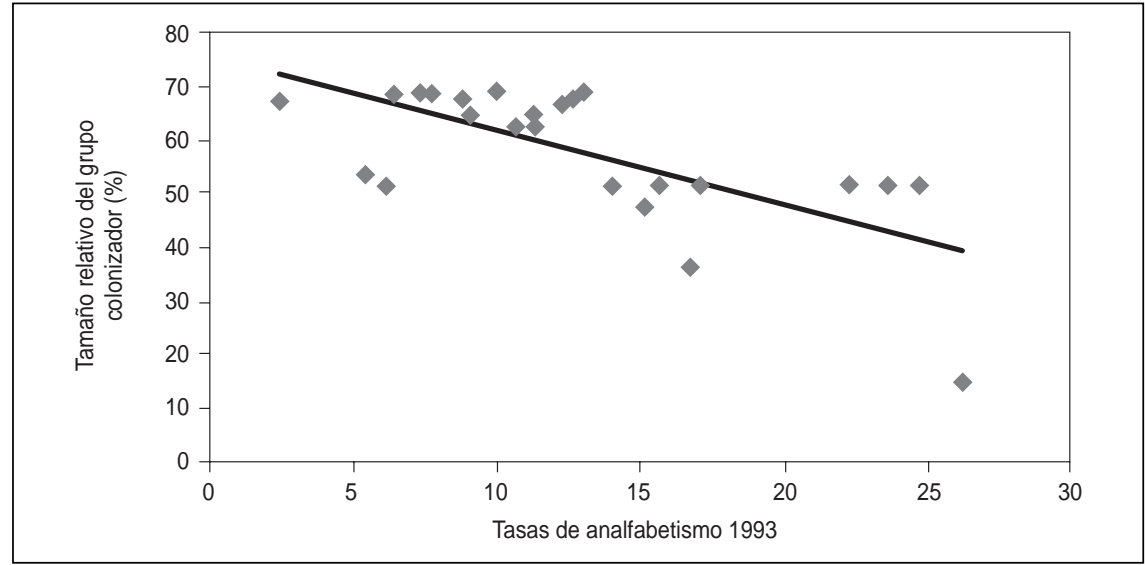

Fuente: Estimaciones de los autores con base en DNP-SISD y Yunis (2003).

GRÁFICO 7

PORCENTAJE DE SUELOS CÁLIDOS Y TASA DE ANALFABETISMO DE 1993

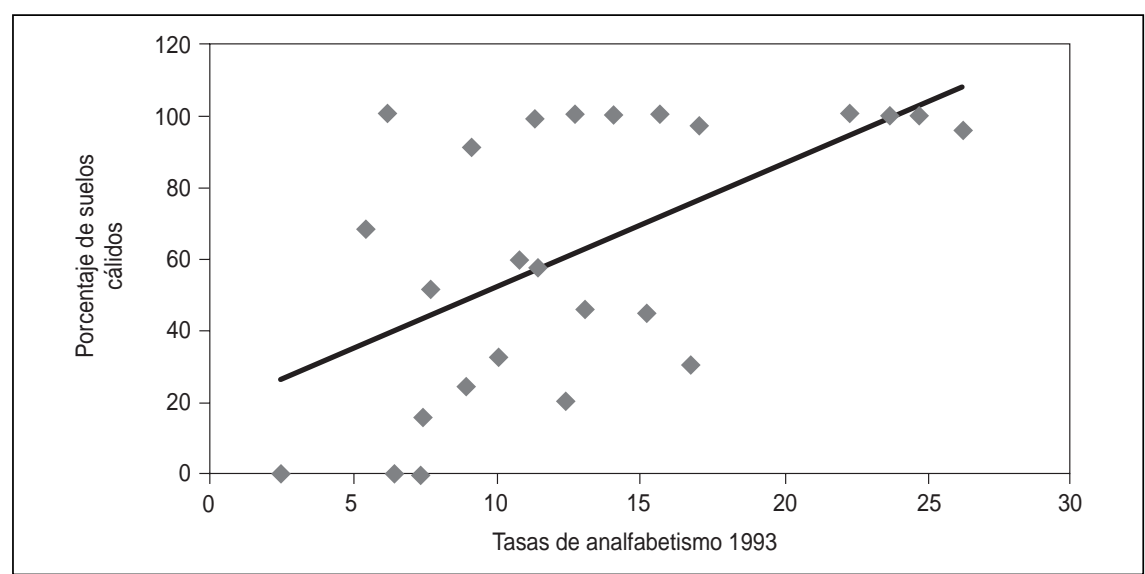

Fuente: Estimaciones de los autores con base en IGAC y Yunis (2003).

cálidos y la participación de la población de origen europeo $(-0,45)$. La evidencia anterior estaría indicando que, como lo sugieren Gleaser et al. (2004), la estimación con variables instrumentales es imperfecta porque 
la variable instrumental está correlacionada con los errores. Esto implicaría que la geografía afecta el ingreso per cápita departamental por varios canales además de las instituciones, por ejemplo a través del capital humano.

Una de las limitaciones en el análisis de la influencia del capital humano en el desempeño económico de largo plazo en Colombia es que no se cuenta con información de analfabetismo durante el período colonial y en los siglos anteriores. Los datos más antiguos con que se cuenta corresponden al porcentaje de estudiantes en 1917, los cuales están disponibles para 14 entidades territoriales (Ramírez y Tellez, 2004). Como puede verse en el gráfico 8 , existe una relación inversa entre el porcentaje de estudiantes de 1917 y la tasa de analfabetismo de 1993, lo cual evidencia el alto grado de persistencia en el nivel regional del capital humano en Colombia ${ }^{16}$.

\section{GRÁFICO 8}

ALUMNOS POR HABITANTES 1917 VS. TASA DE ANALFABETISMO 1993.

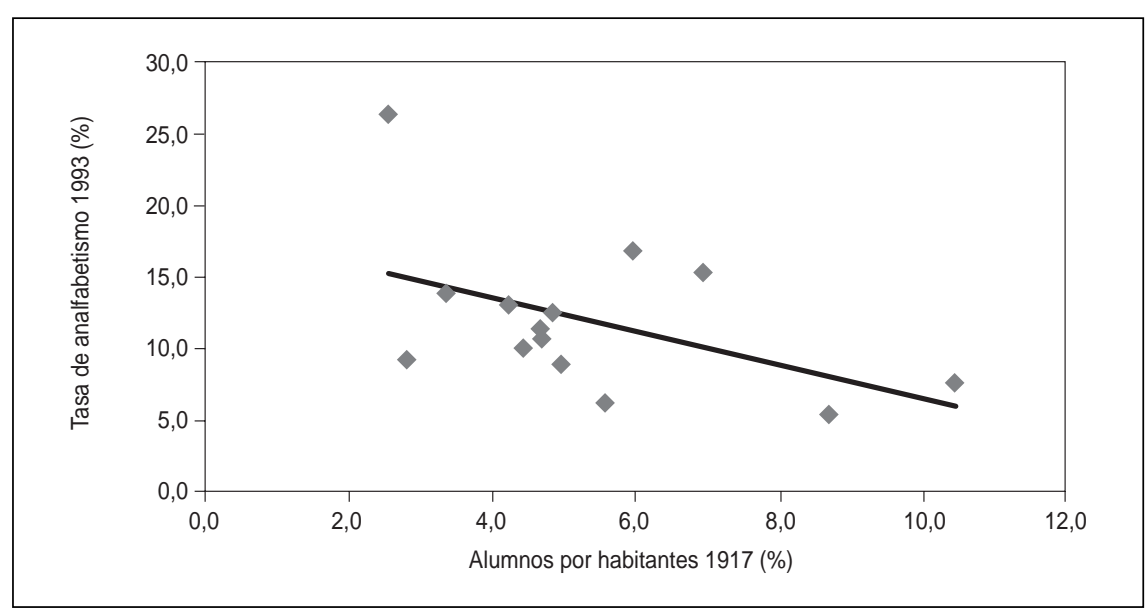

Fuente: Estimaciones de los autores con base en DNP y Ramírez y Tellez.

Siguiendo lo señalado por Gleaser et al. (2004), el modelo estimado por mínimos cuadrados en dos etapas, especificado en las ecuaciones (2) y (3), se ha calculado nuevamente incluyendo la tasa de analfabetis-

16 El coeficiente de correlación entre el número de alumnos por habitantes de 1917 y la tasa de analfabetismo de 1993 es de -0,48, estadísticamente significativo al 8 por cien. 
mo en vez del tamaño relativo del grupo colonizador como variable explicativa. Es de esperarse una relación inversa entre la tasa de analfabetismo y el nivel del ingreso per cápita departamental. Los resultados de la estimación incluida en el cuadro 3, indican que la tasa de analfabetismo resultó ser estadísticamente significativa y con el signo esperado. Nuevamente, las variables dummy resultan robustas. Sin embargo, con la información disponible y los métodos de estimación no es posible escoger entre los modelos que hemos estimado a lo Acemoglu y a lo Glaeser. En otras palabras, se puede afirmar que a pesar de existe una evidencia que apoya una relación entre el legado colonial y los niveles de desarrollo actual en los departamentos colombianos, no es posible determinar si el canal de esa influencia se da vía instituciones o capital humano.

\section{CUADRO 3}

RESULTADO DE LA REGRESIÓN CON VARIABLES INSTRUMENTALES

\begin{tabular}{|c|c|}
\hline \multicolumn{2}{|c|}{ Segunda etapa } \\
\hline \multicolumn{2}{|c|}{ Variable dependiente: logaritmo del ingreso departamental bruto per cápita 2000} \\
\hline Tasa de analfabetismo estimada 1993 & $\begin{array}{c}-0,036 \\
(-3,24) * * *\end{array}$ \\
\hline Dummy Bogotá & $\begin{array}{c}0,96 \\
(7,98) * * *\end{array}$ \\
\hline Dummy Nuevos & $\begin{array}{c}0,25 \\
(5,57)^{* * *}\end{array}$ \\
\hline $\mathbf{R}^{2}$ ajustado & 0,76 \\
\hline Número de observaciones & 25 \\
\hline \multicolumn{2}{|c|}{ Primera etapa } \\
\hline \multicolumn{2}{|c|}{ Variable dependiente: tasa de analfabetismo 1993} \\
\hline Suelos cálidos & $\begin{array}{c}0,094 \\
(3,20) * * *\end{array}$ \\
\hline Dummy Bogotá & $\begin{array}{c}-4,91 \\
(-3,57) * * *\end{array}$ \\
\hline Dummy Nuevos & $\begin{array}{c}-5,27 \\
(-2,59) * *\end{array}$ \\
\hline $\mathbf{R}^{2}$ ajustado & 0,30 \\
\hline Número de observaciones & 25 \\
\hline
\end{tabular}

Los parámetros del modelo tienen errores estándar consistentes a heteroscedasticidad. La correción se realizó usando el método propuesto por White. El valor reportado entre paréntesis corresponde al estadístico $t$. El intercepto no se reporta. Para evaluar la significancia de los coeficientes se usaron los valores críticos de la distribución $t$, los cuales son pertinentes en el tamaño de la muestra. * significativo al 10 por cien. ** significativo al 5 por cien. *** significativo al 1 por cien. 


\section{CONCLUSIONES}

En los últimos años de la década de 1990, se generó un gran interés entre los economistas por el estudio empírico de los determinantes del crecimiento económico en el largo plazo. En esta literatura hay varias orientaciones. Algunos autores le dan más énfasis al papel de las instituciones, otros a la geografía y finalmente otros a la cultura. Este trabajo utiliza los aportes teóricos y empíricos de la reciente bibliografía internacional sobre los determinantes últimos del crecimiento económico de largo plazo, para entender el origen de las enormes desigualdades económicas regionales que caracterizan a Colombia.

En general, los resultados de las estimaciones permiten afirmar que una porción importante de las diferencias observadas en el ingreso per cápita departamental en la actualidad son explicadas por los modelos empleados. Los resultados muestran claramente que, una vez controlados los problemas de especificación y la variabilidad introducida por los fenómenos recientes de Bogotá y Nuevos Departamentos, el legado colonial explica gran parte de las disparidades en el ingreso regional. Las limitaciones de la metodología empleada no permiten determinar el canal a través del cual influyó el legado colonial. La evidencia indica que pudo ser vía instituciones o capital humano. Para entender mejor este proceso es necesario recurrir al estudio detallado de la historia del desarrollo regional colombiano.

No obstante las restricciones del análisis, se encuentra que el tamaño relativo del grupo colonizador tiene una gran importancia en la determinación de las diferencias en el ingreso per cápita departamental. Su distribución coincide con la distribución de la prosperidad material en Colombia. Este hecho ya había sido analizado en el pasado por algunos historiadores, tales como Jaime Jaramillo Uribe. La razón para esta correlación espacial es que los conquistadores y colonizadores españoles crearon en el período colonial instituciones muy desiguales en las diferentes regiones de lo que hoy es Colombia. En unas partes esas instituciones fueron especialmente explotadoras para la mayoría de la población y en otras fueron más igualitarias.

Uno de los departamentos donde las instituciones que se crearon en la colonia se caracterizaron más por la desigual distribución de las oportunidades y la riqueza fue el Chocó. Allí, en 1778, de una población de 14.662 personas, sólo 332, el 2,2 por cien, eran de origen europeo, mientras que había 11.170 indígenas y esclavos; es decir, el 76,2 por cien de la población (Sharp, 1976). En la actualidad, el Chocó tiene un ingreso per cápita que es solo el 30 por cien del ingreso per cápita promedio nacional. En contraste, en 1778, Bogotá tenía 7.731 habitantes de origen europeo, el 48,3 por cien de la población, y solo 2.244 esclavos e indíge- 
nas, es decir el 14 por cien de la población. En el año 2000, el ingreso per cápita de Bogotá, el más alto del país, estuvo 240 por cien por encima del promedio nacional.

Adicionalmente, el capital humano, medido a través de la tasa de analfabetismo de 1993, muestra una alta correlación con el patrón de poblamiento del grupo colonizador y con nuestra variable geográfica (porcentaje de suelos cálidos). Esto nos indicaría que la influencia del legado colonial también pudo haber sido vía capital humano, tal y como lo sugieren Gleaser et al.

\section{BIBLIOGRAFÍA}

Acemoglu, D.; Johnson, S., y Robinson, S. (2001): «The Colonial Origins of Comparative Development: An Empirical Investigation», American Economic Review, 91 (5), pp. 1369-1401.

- (2002): «Reversal of Fortune: Geography and Institutions in the Making of the Modern World Income Distribution», The Quarterly Journal of Economics, 117, pp. 1231-1294.

- (2005): «Institutions as a Fundamental Cause of Long-Run Growth», en P. Aghion y S. Durlauf (eds.), Handbook of Economic Growth, V. 1A, capítulo 6.

Bonet, J., y Meisel, A. (2006): «Polarización del ingreso per cápita departamental en Colombia, 1975-2000», Documentos de Trabajo sobre Economía Regional, 76, Banco de la República, Centro de Estudios Económicos Regionales-CEER, Cartagena de Indias.

DNP (2003): Diez años de desarrollo humano en Colombia, Bogotá.

CEGA (2006): Ingreso, consumo y ahorro en los departamentos de Colombia, 19752000, vol. 2, Sistema Simplificado de Cuentas Departamentales, Bogotá.

Easterly, W., y Levine, R. (2003): «Tropics, Germs and Crops: How Endowments Influence Economic Development», Journal of Monetary Economics, 50 (1), pp. 3-39.

ENGERMAN, S., y SoKolofF, K. (1997): «Factor Endowments, Institutions, and Differential Paths of Growth Among New World Economies», en S. HABER (ed.), How Latin America Fell Behind, Stanford University Press.

FERNÁNDEZ, C. (1998): "Agglomeration and Trade: The Case of Colombia», Ensayos sobre Política Económica, 33, pp. 85-122.

Gallup, J. L.; SAchs, J., y Mellinger, A. (1999): «Geography and Economic Development», Center for International Development, Harvard University, Working Paper No. 1.

Galvis, L. A. (2001): "Determinantes de la migración interdepartamental en Colombia, 1988-1993», Documento de Trabajo sobre Economía Regional, 29, Cartagena: Banco de la República.

- (2001): "¿Qué determina la productividad agrícola departamental en Colombia?», en A. MeIsel (ed.), Regiones, ciudades y crecimiento económico en Colombia, Cartagena: Colección de Economía Regional-Banco de la República.

GAMARRA, J. (2006): "Corrupción, participación política y pobreza: una revisión para el caso colombiano", Documento de Trabajo sobre Economía Regional, 70, Cartagena: Banco de la República. 
GARCíA, C. (2005): «Colonial Institutions and Long-Run Economic Performance in Colombia: Is There Evidence of Persistence?», Documento CEDE, 2005-59. Bogotá: Universidad de Los Andes.

Glaeser, E.; La Porta, R; López-De-Silanes, F., y Shleifer, A. (2004): «Do Institutions Cause Growth?», Journal of Economic Growth, 9, pp. 271-303.

Hall, R., y Jones, C. (1999): «Why Do Some Countries Produce So Much More Output per Worker than Others?», The Quarterly Journal of Economics, CXIV, pp. 83-116.

JARAMILLO, S. (1999): «Migraciones e interacción regional en Colombia, 19731993», Territorios, 1, pp. 95-117, Universidad de los Andes, Bogotá.

JaRAmillo Uribe, J. (1989): Ensayos de historia social, tomo II, Bogotá: Tercer Mundo Editores-Ediciones Uniandes.

Kalmanovitz, S. (2001): Las instituciones y el desarrollo económico en Colombia, Bogotá: Editorial Norma, S. A.

Knack, S., y Keefer, P. (1995): «Institutions and Economic Performance: Crosscountry Tests Using Alternative Institutional Measures», Economics and Politics, 7, pp. 207-227.

- (1997): «Does Social Capital Have an Economic Payoff? A Cross-Country Investigation», The Quarterly Journal of Economics, 112, 4, pp. 1251-1288.

Krugman, P., y Livas, R. (1996): "Trade Policy and the Third World Metropolis», Journal of Development Economics, 49, pp. 137-150.

McArthur, J., y SACHS, J. (2001): «Institutions and Geography: Comment on Acemoglu, Johnson, and Robinson (2000)», NBER Working Paper, 8114.

North, D. (1990): Institutions, Institutional Change, and Economic Performance, Cambridge, Cambridge University Press.

RAMíREZ, M., y TELLEZ, J. (2004): «La educación primaria y secundaria en Colombia en el siglo XX», Borradores de Economía, 379, Bogotá: Banco de la República.

Rodrik, D.; SubBramanian, A., y TrebBi, F. (2004): «Institutions Rule: The Primacy of Institutions Over Geography and Integration in Economic Development», Journal of Economic Growth, 9 (2), pp. 131-165.

Rodríguez, J. V. (2003): «Avances de la antropología dental en Colombia», bajado del Internet en la dirección http://www.colciencias.gov.co/seiaal/documentos/ jurc06c7.html, el día 16 de junio del 2003.

Sala-I-Martín, X. (1997): "I Just Ran Two Million Regressions», The American Economic Review, 87, 2, pp. 178-183.

SACHS, J. (2001): «Tropical Underdevelopment», NBER Working Paper, 8119.

SHARP, W. (1976): Slavery on the Spanish Frontier, The Colombian Choco, 1680-1810, University of Oklahoma, USA.

TABellini, G. (2005): Culture and Institutions: Economic Development in the Regions of Europe, IGIER, Bocconi University.

Weber, M. (1930), The Protestant Ethic and the Spirit of Capitalism, London: Allen and Unwin.

Yunis, E. (2003), ¿Por qué somos así? ¿Qué pasó en Colombia? Análisis del Mestizaje, Bogotá: Temis. 


\section{ANEXO 1}

PRUEBA DE CONFIANZA DE LAS VARIABLES

(VARIABLE DEPENDIENTE = INGRESO PER CÁPITA)

\begin{tabular}{|c|c|c|c|c|}
\hline Variable independiente & Media & $\begin{array}{c}\text { Desviación } \\
\text { estándar }\end{array}$ & Probabilidad & $\begin{array}{l}\text { Número de } \\
\text { regresiones }\end{array}$ \\
\hline $\begin{array}{l}\quad \text { Modelo } 1 \\
\text { Constante } \\
\text { Temperatura } \\
\text { Altitud } \\
\text { FHT } \\
\text { Fertilidad de suelos } \\
\text { Dummy mar } \\
\text { Población en cálidos } \\
\text { Suelos cálidos } \\
\text { Religiosos } 1843 \\
\text { Religiosos } 1851 \\
\text { Porcentaje de católicos } \\
\text { Participación electoral } \\
\text { Tamaño relativo grupo } \\
\text { colonizador } \\
\text { Dummy Bogotá } \\
\text { Dummy Nuevos }\end{array}$ & $\begin{array}{r}12,66 \\
0,03 \\
0,00 \\
0,00 \\
0,02 \\
0,20 \\
0,00 \\
-0,16 \\
95,81 \\
-30,94 \\
0,50 \\
0,13 \\
\\
1,60 \\
1,08 \\
0,35\end{array}$ & $\begin{array}{r}0,98 \\
0,06 \\
0,00 \\
0,00 \\
0,44 \\
0,16 \\
0,00 \\
0,32 \\
128,15 \\
57,41 \\
1,20 \\
0,57 \\
\\
0,57 \\
0,73 \\
0,29\end{array}$ & $\begin{array}{l}1,00 \\
0,70 \\
0,62 \\
0,54 \\
0,52 \\
0,90 \\
0,69 \\
0,70 \\
0,77 \\
0,71 \\
0,66 \\
0,59 \\
1,00 \\
0,93 \\
0,88\end{array}$ & $\begin{array}{r}180 \\
50 \\
50 \\
50 \\
50 \\
50 \\
50 \\
50 \\
29 \\
29 \\
29 \\
29 \\
\\
180 \\
180 \\
180\end{array}$ \\
\hline $\begin{array}{l}\quad \text { Modelo } 2 \\
\text { Constante } \\
\text { Temperatura } \\
\text { Altitud } \\
\text { FHT } \\
\text { Fertilidad de suelos } \\
\text { Dummy mar } \\
\text { Población en cálidos } \\
\text { Suelos cálidos } \\
\text { Religiosos } 1843 \\
\text { Religiosos } 1851 \\
\text { Porcentaje de católicos } \\
\text { Participación electoral } \\
\text { Esclavos } 1843 \\
\text { Dummy Bogotá } \\
\text { Dummy Nuevos }\end{array}$ & $\begin{array}{r}13,53 \\
0,05 \\
0,00 \\
0,00 \\
-0,31 \\
0,01 \\
0,00 \\
-0,43 \\
59,27 \\
-27,95 \\
0,52 \\
0,89 \\
-3,10 \\
1,21 \\
0,41\end{array}$ & $\begin{array}{r}1,08 \\
0,06 \\
0,00 \\
0,00 \\
0,50 \\
0,19 \\
0,00 \\
0,35 \\
172,21 \\
69,17 \\
1,50 \\
0,46 \\
3,65 \\
0,95 \\
0,35\end{array}$ & $\begin{array}{l}1,00 \\
0,80 \\
0,65 \\
0,61 \\
0,73 \\
0,52 \\
0,81 \\
0,89 \\
0,63 \\
0,66 \\
0,63 \\
0,97 \\
0,80 \\
0,90 \\
0,88\end{array}$ & $\begin{array}{r}180 \\
50 \\
50 \\
50 \\
50 \\
50 \\
50 \\
50 \\
29 \\
29 \\
29 \\
29 \\
180 \\
180 \\
180\end{array}$ \\
\hline $\begin{array}{l}\quad \text { Modelo } 3 \\
\text { Constante } \\
\text { Temperatura } \\
\text { Altitud } \\
\text { FHT } \\
\text { Fertilidad de suelos }\end{array}$ & $\begin{array}{r}13,53 \\
0,06 \\
0,00 \\
0,00 \\
-0,33\end{array}$ & $\begin{array}{l}1,08 \\
0,06 \\
0,00 \\
0,00 \\
0,51\end{array}$ & $\begin{array}{l}1,00 \\
0,82 \\
0,64 \\
0,69 \\
0,74\end{array}$ & $\begin{array}{r}180 \\
50 \\
50 \\
50 \\
50\end{array}$ \\
\hline
\end{tabular}




\begin{tabular}{|l|r|c|c|c|}
\hline Variable independiente & Media & $\begin{array}{c}\text { Desviación } \\
\text { estándar }\end{array}$ & Probabilidad & $\begin{array}{c}\text { Número de } \\
\text { regresiones }\end{array}$ \\
\hline Dummy mar & 0,02 & 0,21 & 0,53 & 50 \\
Población en cálidos & 0,00 & 0,00 & 0,82 & 50 \\
Suelos cálidos & $-0,45$ & 0,35 & 0,90 & 50 \\
Religiosos 1843 & 43,64 & 178,85 & 0,60 & 29 \\
Religiosos 1851 & $-23,63$ & 70,81 & 0,63 & 29 \\
Porcentaje de católicos & 0,24 & 1,49 & 0,57 & 29 \\
Participación electoral & 0,96 & 0,46 & 0,98 & 29 \\
Esclavos 1851 & $-3,52$ & 6,52 & 0,71 & 180 \\
Dummy Bogotá & 1,24 & 0,98 & 0,90 & 180 \\
Dummy Nuevos & 0,44 & 0,39 & 0,87 & 180 \\
\hline
\end{tabular}

Fuente: Estimaciones de los autores.

Nota: Los modelos se estimaron por mínimos cuadrados ordinarios. En cada modelo se verificó la confidencia de cada una de las variables proxy para las instituciones combinando diferentes variables de control. La media corresponde al valor medio del coeficiente estimado en las diferentes regresiones en que participó la variable. Para estimar la significancia del coeficiente, se asumió una distribución normal.

ANEXO 2

ESTADÍSTICAS DESCRIPTIVAS DE LAS VARIABLES

\begin{tabular}{|l|r|r|r|r|r|r|}
\hline \multicolumn{1}{|c|}{ Variable } & \multicolumn{1}{|c|}{ Media } & Mediana & Máximo & Mínimo & $\begin{array}{c}\text { Desviación } \\
\text { estándar }\end{array}$ & $\begin{array}{c}\text { Número } \\
\text { de obser- } \\
\text { vaciones }\end{array}$ \\
\hline Ingreso per cápita 2000 & 1.221 .011 & 1.170 .236 & 4.063 .386 & 490.878 & 678.948 & 25 \\
Altitud & 892 & 829 & 2.600 & 20 & 789 & 25 \\
Temperatura & 23 & 24 & 28 & 13 & 4 & 25 \\
Fertilidad & 27 & 24 & 74 & 4 & 19 & 25 \\
Índice FHT & 77 & 73 & 320 & -39 & 91 & 25 \\
Suelos cálidos & 61 & 59 & 100 & 0 & 38 & 25 \\
Distancia de Bogotá & 594 & 562 & 1.486 & 0 & 435 & 25 \\
Población en & & & & & & \\
clima cálido & 59 & 68 & 100 & 0 & 41 & 25 \\
Tamaño relativo del & & & & & 13 & 25 \\
grupo colonizador & 58 & 61 & 73 & 15 & 2,27 & 25 \\
Esclavos 1843 & 1,93 & 1,04 & 9,12 & 0,00 & 1,34 & 25 \\
Esclavos 1851 & 1,06 & 0,70 & 4,30 & 0,00 & 18 & 25 \\
Participación electoral & 53 & 58 & 86 & 21 & 0,23 & 25 \\
Religiosos 1843 & 0,12 & 0,06 & 1,22 & 0,00 & 0,26 & 25 \\
Religiosos 1851 & 0,15 & 0,06 & 1,32 & 0,00 & 6,3 & 25 \\
Analfabetos 1993 & 12,3 & 11,0 & 26,0 & 2,0 & \\
\hline
\end{tabular}

Fuente: Estimaciones de los autores. 